Ann. Zootech., 1977, 26 (I), 99-103

\title{
Note
}

\section{Effet d'une variation du taux de chlore dans l'alimentation du lapin en croissance}

\author{
M. COLIN \\ avec la collaboration technique de G. SARd \\ Laboratoire de Recherches sur l'Élevage du Lapin, \\ Centre national de Recherches zootechniques, I.N.R.A., \\ 78350 Jouy-en-Josas (France)
}

\section{Résumé}

Trente trois lapereaux âgés de 35 jours sont répartis entre 3 aliments différant uniquement par leur taux de chlore $(0,17-0,32-0,47 \mathrm{p}$. I0o). Les résultats obtenus montrent qu'un régime apportant 0,17 p. Ioo de chlore est carencé en cet élément. Par ailleurs, on n'observe aucune différence entre les performances des lapins recevant les rations contenant 0,32 ou $0,47 \mathrm{p}$. roo de chlore.

\section{Introduction}

Les besoins en minéraux du Lapin restent encore très mal connus (LEBAS, I969). En particulier, on ignore les conséquences d'une variation du taux de chlore de la ration sur la croissance de cet animal. Nous avons donc recherché les effets d'une augmentation du taux de chlore dans l'aliment sur les performances zootechniques du Lapin.

\section{Matériel et méthodes}

\section{Animaux}

Trente-trois lapins californiens des 2 sexes, âgés de 35 ou 36 jours en début d'expérience sont répartis entre les 3 régimes expérimentaux. Leurs performances de croissance et de consommation sont étudiées pendant 6 semaines par des méthodes déjà décrites (CoLIN, I974). 
TABLEAU I

Composition des régimes expérimentaux (p. roo)

Composition of experimental diets ( $p$. Ioo)

\begin{tabular}{|c|c|c|c|}
\hline $\begin{array}{l}\text { Chlore apporté par le complément minéral } \\
\text { (chlorine added through minerals) }\end{array}$ & 0 & $0, \mathrm{I} 86$ & 0,375 \\
\hline 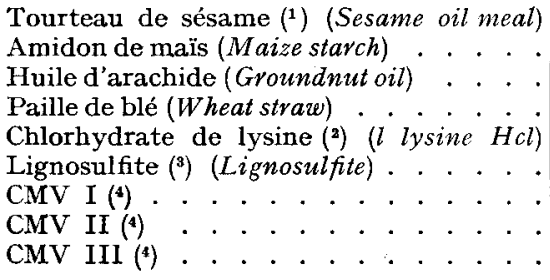 & $\begin{array}{l}39 \\
34,7^{0} \\
3 \\
20 \\
0,34 \\
1 \\
1,96 \\
- \\
-\end{array}$ & $\begin{array}{c}39 \\
34,84 \\
3 \\
20 \\
0,34 \\
1 \\
-\overline{1,82} \\
-\end{array}$ & $\begin{array}{c}39 \\
34,68 \\
3 \\
20 \\
0,34 \\
1 \\
- \\
- \\
1,98\end{array}$ \\
\hline 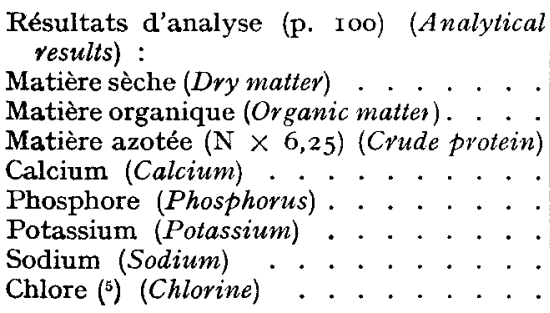 & $\begin{array}{l}90,1 \\
80,7 \\
18,7 \\
1,11 \\
0,72 \\
0,56 \\
0,26 \\
0,17\end{array}$ & $\begin{array}{l}89,9 \\
80,3 \\
18,7 \\
1,07 \\
0,73 \\
0,54 \\
0,25 \\
0,32\end{array}$ & $\begin{array}{c}89,9 \\
80,0 \\
18,5 \\
1,09 \\
0,70 \\
0,54 \\
0,24 \\
0,37\end{array}$ \\
\hline
\end{tabular}

(i) 39,7 p. 100 de matières azotées. $(39,7$ p. $x 00$ crude protein.)

$\left({ }^{2}\right)$ Produit commercialisé par Rousselor Kulmman, contenant 95 p. Ioo de L, lysine $\mathrm{HCl}$, soit 80 p. roo de lysine base (Brevet Ajinomoto, Tokyo). (Commercialised by Roussecot-KulHman, containing 95 p. roo of L lysine $\mathrm{HCl}$ i.e. 80 p. 100 of pure lysine (Patent Ajinomoto Tokyo Japan).)

(3) Lignosulfite "NARSILUC " commercialisé par RousSElot KulHMaN utilisé comme liant destiné à améliorer l'agglomération de l'aliment. (Lignosulfite "NARSILUC " commercialised by ROUSSELOT-KULHMaN employed to improve the pellet quality.)

( ${ }^{4}$ ) Minéraux, voir tableau 2; Vitamines, Colin, Arkhurst et Lebas (I973). (Minerals: see table 2 ; Vitamins: Colin, ARKHURST and I EBAS (I973).)

(5) Dosage indirect après réaction sur du thiocyanate mercurique, et dosage des ions thiocyanate libérés, par du nitrate ferrique. (Indirect determination after reaction of mercuric thiocyanate and quantitative analysis of thiocyanate ions obtained, by reaction with ferric nitrate.)

Les animaux sont logés dans des cages individuelles entièrement métalliques, munies d'abreuvoirs à surface d'eau libre.

\section{Régimes}

Les lapins reçoivent ad libitum l'un des 3 aliments expérimentaux sous forme de granulés de $2,5 \mathrm{~mm}$ de diamètre (tabl. I). Ces régimes semi-purifiés à base de tourteau de sésame sont choisis aussi bien en raison des performances de haut niveau qu'ils permettent (CoLIN, I974) qu'à cause des faibles teneurs en chlore et en potassium de la ration de base. 
TABLEAU 2

Composition des compléments minéraux (p. Ioo)

Added minerals ( $p$. Ioo of total added minerals)

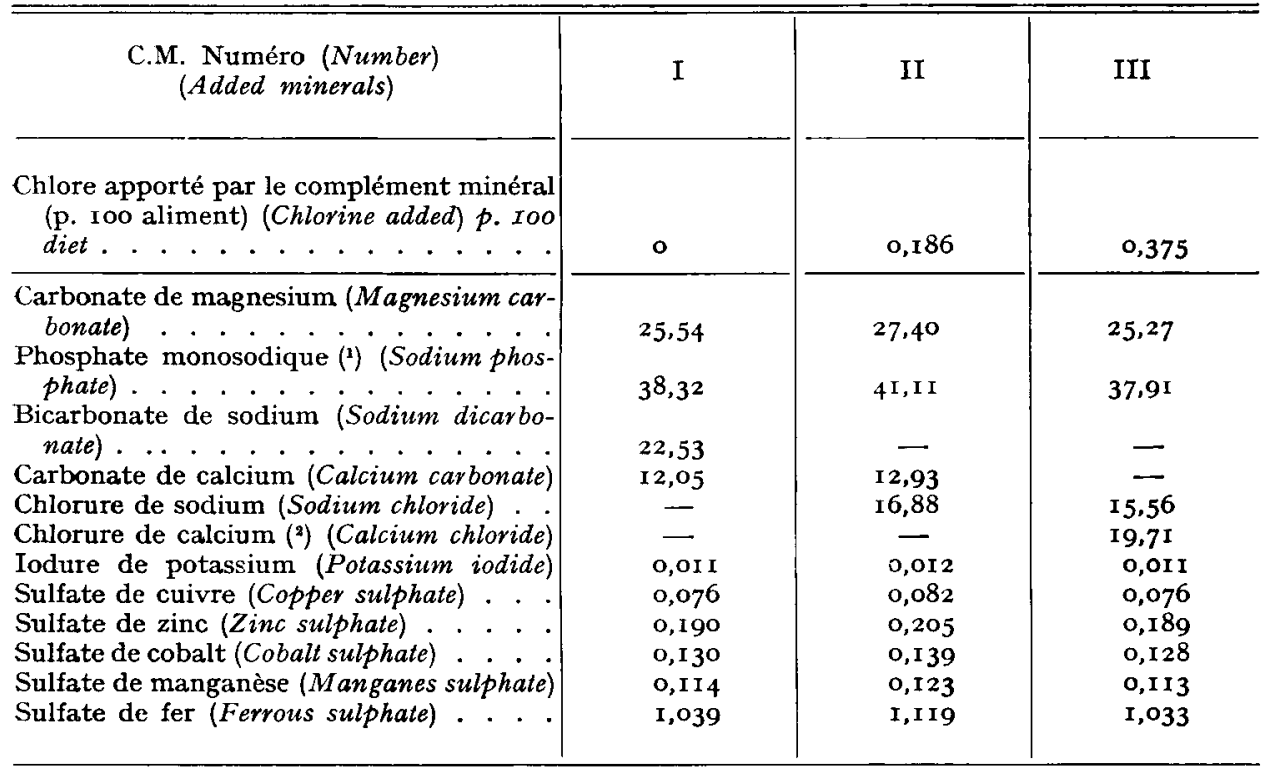

(1) Cristallisé $\mathrm{NaH}_{2} \mathrm{PO}_{4}, 2 \mathrm{H}_{2} \mathrm{O}$. (Cristallized.)

(2) Cristallisé $\mathrm{CaCl}_{2}, 2 \mathrm{H}_{2} \mathrm{O}$. (Cristallized.)

Le taux de chlore est augmenté par apport de chlorure de sodium et de chlorure de calcium en remplacement du bicarbonate de sodium et du carbonate de calcium (tabl. 2).

\section{Résultats et discussion}

L'élévation du taux de chlore de $0, I_{7}$ p. Ioo à 0,32 p. Ioo du régime augmente fortement le gain de poids ( 5 p. IOo) des lapins (tabl. 3). Cette amélioration de la croissance semble essentiellement due à une action du chlore sur la quantité d'aliment ingérée tandis que l'indice de consommation n'est pas affecté.

Ces observations tendent à prouver qu'une teneur en chlore inférieure à $0,20 \mathrm{p}$. roo de l'aliment est insuffisante pour permettre une croissance optimale du Lapin. Il convient de souligner que les effets de cette déficience en chlore sont observés avec un régime apportant le sodium et le potassium à des taux égaux ou même légèrement inférieurs aux besoins du Lapin (Surdeau, Henaff et Perrier, 1976). Or LeAch et Nesheim (Ig63) ont montré chez le Poulet que les conséquences d'une carence en chlore sont d'autant plus marquées que l'aliment contient plus de sodium et de potassium. Il est donc possible qu'avec une ration pour Lapin de type pratique (généralement riche en potassium), la dépression de croissance due à un 


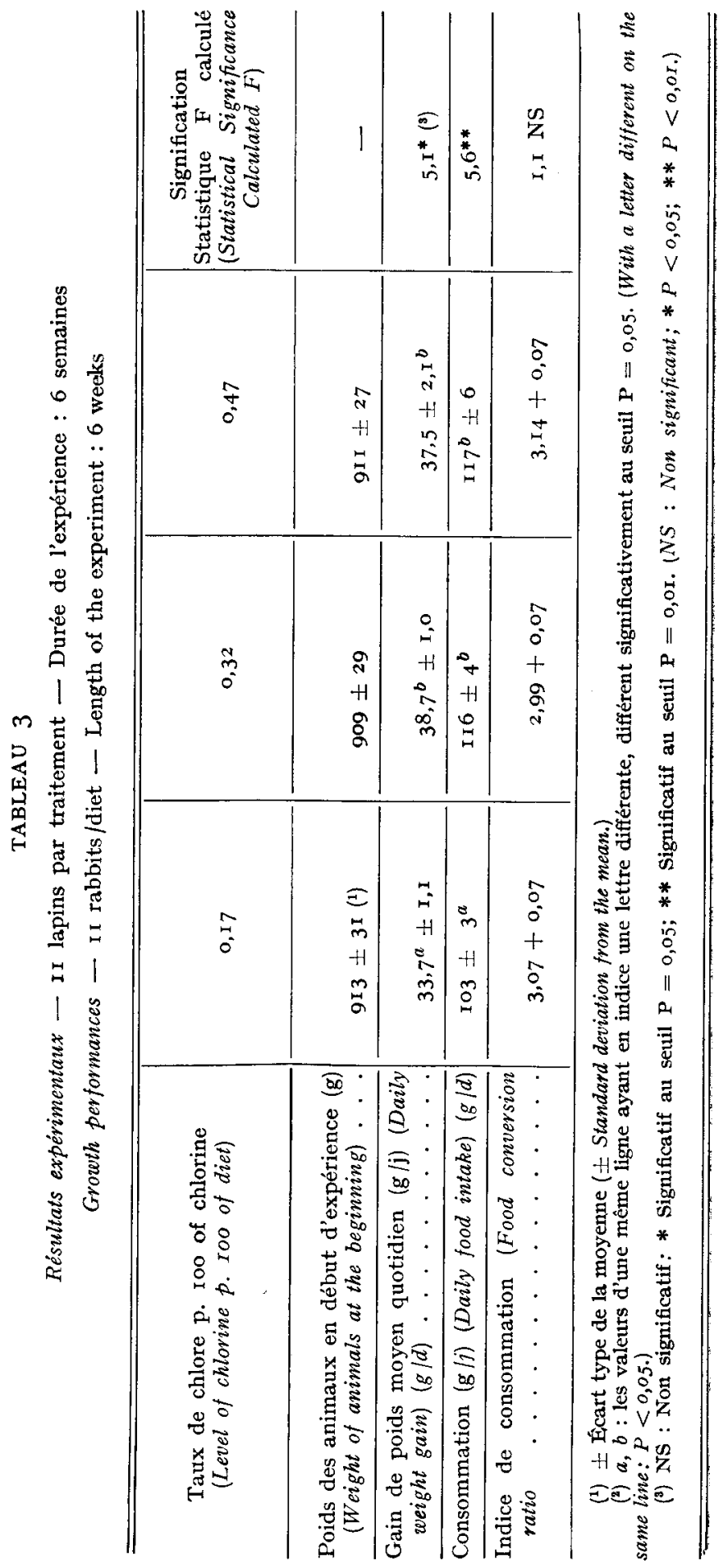


apport insuffisant de chlore soit plus importante que celle observée dans l'expérience présentée ici.

Les performances enregistrées avec $0,47 \mathrm{p}$. Ioo de chlore sont identiques à celles obtenues avec 0,32 p. roo. Il ne semble donc pas que des déséquilibres par excès de chlore se manifestent en dessous de $0,50 \mathrm{p}$. Ioo de cet élément. Ce résultat paraît pouvoir être généralisé aux aliments habituellement utilisés dans l'élevage du Lapin puisque, chez d'autres espèces, les effets éventuels d'un apport trop élevé de chlore sont moins accentués avec une ration riche en sodium et en potassium qu'avec des régimes pauvres comme ceux utilisés ici (MongIN et SAUveUR, I973).

En conclusion, s'il ne permet pas de fixer avec précision les besoins en chlore du Lapin en croissance, ce travail semble indiquer que des taux de chlore compris entre 0,30 et $0,50 \mathrm{p}$. Ioo permettent d'éviter des déséquilibres marqués en cet élément. Il conviendra toutefois de vérifier la validité de cette recommandation pour des régimes plus riches en sodium et en potassium.

Rę̧u pour publication en décembre 1976.

\section{Summary}

\section{Effect of varying the chlorine level in growing rabbit diets}

Thirty three 35 days old rabbits were distributed into three groups receiving diets only differring by their chlorine content (o.17, 0.32 and $0.47 \mathrm{p}$. cent). Results obtained show that a diet supplying o.I 7 p. cent chlorine is deficient in this element. Furthermore, no differences were observed between the performances of the rabbits receiving the diets containing 0.32 or 0.47 p. cent chlorine.

\section{Références bibliographiques}

Colın M., 1974. Supplémentation en lysine d'un régime à base de tourteau de sésame chez le Lapin. Effets sur les performances de croissance et le bilan azoté estimé par deux méthodes. Ann. Zootech., 23, I I9-I32.

Colin M., Arkhurst G., Lebas F., i973. Effets de l'addition de méthionine au régime alimentaire sur les performances de croissance chez le Lapin. Ann. Zootech., 22, 485-49I.

Leach R. M., Nesheim M. C., I963. Studies on chloride deficiency in the chicks. J. Nutr., 81, 193-199.

Lebas F., 1969. L'alimentation du Lapin. Bull. Soc. Sci. Hyg. Alim., 57, 245-268.

Mongin P., Sauveur B., 1973. Effets des teneurs en chlore, sodium et potassium du régime sur la croissance du Poulet et l'apparition des anomalies cartilagineuses. Journées Rech. Avicole et Cunicole, I87-192, I.T.A.V.I. éd. Paris.

Surdeau P., Henaff R., Perrier G., I976. Apport et équilibre alimentaire du sodium, du

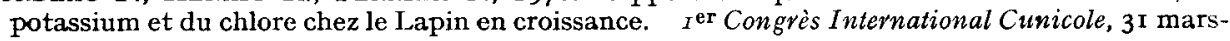
2 avril 1976. Dijon, France. 